Acta Technologica Agriculturae 1

Nitra, Slovaca Universitas Agriculturae Nitriae, 2019, pp. 1-4

\title{
EFFECT OF DIFFERENT RATIOS OF BIOMATERIALS TO BANANA PEELS ON THE WEIGHT LOSS OF BIODEGRADABLE POTS
}

\author{
Siti Nor Amirah MOHD RAFEE, Yit Leng LEE*, Mohd Riduan JAMALLUDIN, \\ Norawanis ABDUL RAZAK, Nur lailina MAKHTAR, Ras Izzati ISMAIL \\ Universiti Malaysia Perlis, Kampus Uniciti Alam, Perlis, Malaysia
}

\begin{abstract}
The present study was undertaken to determine the weight loss of pots made of different ratios of biomaterials and banana peels. Two types of biodegradable pots were produced using different ratios of biomaterials $(B)$ and banana peels (BP). The ratios of $B$ to $\mathrm{BP}$ tested in this study were B50\%: BP50\% and B30\%: BP 70\%. The weight loss of biodegradable pot with ratio B30\% : BP70\% was significantly higher than biodegradable pot with ratio B50\%: BP50\% after the empty biodegradable pots were left to decompose on the ground for 60 days. This result suggests that higher content of banana peels increase the microbial decomposition of the biodegradable pot. On the contrary, the weight loss of biodegradable pot with ratio B50\%:BP50\% was higher when they were filled with soil and left to decompose on the ground for 60 days. This is probably due to the lower content of banana peels, what decreased the tensile strength of biodegradable pot filled with soil, making it highly decomposable in such manner. In terms of degradability, biodegradable pot with ratio B30\%: BP70\% is more appropriate than pot with ratio B50\%: BP50\%.
\end{abstract}

Keywords: decomposition; carbon; nitrogen; pot; glycerol; soil

Non-renewable petroleum-based plastic items are widely used in agriculture and plastic waste accumulation imposes pollution problems to environment. Degradation of plastic waste in landfills takes more than 20 years and plastic waste cannot be conventionally recycled due to high level of ash, impurities and heavy metals (Webb et al., 2013). In nursery and floriculture, plastic pots are frequently used for growing plants as they are lightweight, inexpensive, and durable. However, plastic pots are made of inert material and thus non-biodegradable. Plastic pot wastes are often burned or abandoned in the open, buried in soil, as well as disposed of in landfills. Inappropriate disposal of the plastic pot waste causes soil and water contamination, release of harmful substances and air pollutants, as well as soil quality degradation (Briassoulis et al., 2013).

An alternative way of plastic pot usage reduction is to generate biodegradable pots made of plasticizer (glycerol) and solid wastes. Uncountable amount of solid waste has been generated by agricultural production system. Landfills, incineration and environmental dumping have been primary methods for disposal of agricultural solid wastes. Banana is native to regions of Southeast Asia and cultivated throughout the tropics. In Malaysia, banana is the second most widely cultivated fruit, covering approximately 26,000 ha with a total production of 530,000 metric tonnes (Tock et al., 2010). Banana peel waste is normally disposed of in municipal landfills, contributing to existing environmental issues. An alternative management of banana waste is to use it as a fibre ingredient in combination with plasticizer in order to produce a novel product - pot made of biomaterial. Compared with a plastic pot non-degradability, such bio-material pots can be broken down quickly. It was reported that the biomaterial containing less than $50 \%$ of dry matter is easier to be decomposed by the microorganisms (Kažimírová et al., 2018). Biomaterial pots are more environmentally friendly and economically attractive alternative to traditional plastic pots. Moreover, these biodegradable pots can minimize root injury by proper burying of the biomaterial pot into soil together with the seedlings.

Liew and Khor (2015) observed that bioplastic pot made of material with higher content of tapioca starch showed weight loss of approx. $24.9 \%$ in 15 day. Biomaterial in bioplastic pots helps to increase their strength. Biomaterial made of keratin with $2 \%$ of glycerol has the best mechanical and thermal properties (Ramakrishnan et al., 2018). Composition of plastic film affects the biodegradability rate. Literature on this matter reports that the plastic film decomposes at slower rate with the increasing of glycerol content (Ramakrishnan et al., 2018). Nevertheless, there is a scarcity of information on the effect of various concentrations of biomaterial and banana peels mixture on the weight loss of biodegradable pots. Aim of this study was to determine the weight loss of biodegradable pots made of different ratios of biomaterials and banana peels. 


\section{Material and methods}

\section{Samples collection and preparation}

Biomaterials used for the production of biodegradable pots were banana peels, tapioca starch, glycerol with $99.5 \%$ concentration and vinegar. Approximately $8 \mathrm{~kg}$ of banana peels were collected from a fruit stall in Perlis. Banana peels were sun-dried for 3 days and subsequently cut and blended into powder form prior to the production of biodegradable pots.

\section{Production of biodegradable pots}

Biomaterials for the production of biodegradable pots were tapioca starch, water, vinegar and glycerol using the method proposed by Liew and Khor (2015). Appropriate amounts of materials for biodegradable pots were weighed on the basis of ratio of biomaterial to banana peels. Ratios of bio-materials $(\mathrm{B})$ to banana peels $(\mathrm{BP})$ tested in this study were $\mathrm{B} 50 \%$ : $\mathrm{BP} 50 \%$ and $\mathrm{B} 30 \%$ : $\mathrm{BP} 70 \%$. Experiment for each variant was replicated three times. The tapioca starch, water, vinegar and glycerol were added and properly mixed together at room temperature. Mixture was stirred approximately for 2 minutes until it was well-mixed. Then, mixture was heated using hot plate VELP/ITALY at $55^{\circ} \mathrm{C}$ until fully sticky gel texture was obtained. Afterwards, sample was poured into a tray covered with aluminium foil and spread out evenly in the tray. Subsequently, it was oven-dried at $70^{\circ} \mathrm{C}$.

Drying time of the spread varied according to individual mixture ratios. Purpose of drying the spread was to enable easier removal from aluminium foil. Then, the spread of biomaterials and banana peels was removed from aluminium foil and formed by means of plastic pot mould. Formed biodegradable pots were oven-dried at $70{ }^{\circ} \mathrm{C}$ for $24 \mathrm{~h}$ in order to achieve equilibrium with temperature and humidity of the surrounding. Dimensions of biodegradable pot were $9.0 \mathrm{~cm}$ height, $7.2 \mathrm{~cm}$ diameter and $0.2 \mathrm{~cm}$ thickness (Fig. 1).

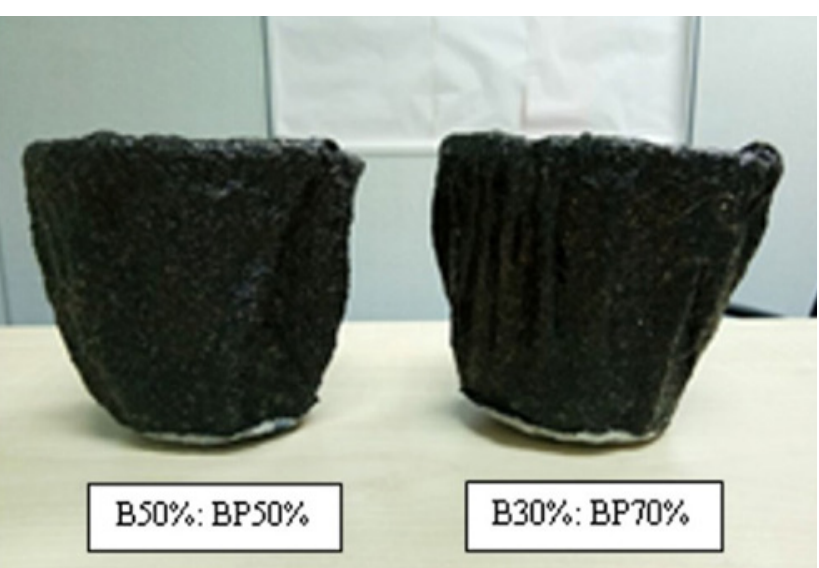

Fig. 1 Biodegradable pots with dimension of $9.0 \mathrm{~cm}$ height, $7.2 \mathrm{~cm}$ diameter and $0.2 \mathrm{~cm}$ thickness

\section{Testing of biodegradable pots}

Decomposition study of biodegradable pots

Degradability of pots was determined using the biodegradable pots filled with and without soil. Three biodegradable pots of each ratio were tested on the ground in order to test the degradability of the pot with soil contact. Initial oven-dried weight of biodegradable pots was taken prior to decomposition study. Biodegradable pots were collected after 3 months-long decomposition on the ground and cleaned from all impurities. Subsequently, they were oven-dried at $70{ }^{\circ} \mathrm{C}$ until a constant weight was obtained. Final weight of each dried biodegradable pot was taken. Weight loss percentages of pots were calculated by using the following formula:

$$
\text { weight loss }(\%)=\frac{W_{1}-W_{f}}{W_{i}} \times 100
$$

where:

$W_{i} \quad$ - initial oven-dried weight (g)

$W_{f} \quad$ - final oven-dried weight (g)

\section{Total carbon and nitrogen analysis}

Elemental contents of total carbon and nitrogen of the biodegradable pots at different ratios were determined using LECO CNS analyser. Analyses were performed three times.

\section{Statistical analysis}

A pair $t$-test was used to detect significant differences between weight loss percentages and contents of carbon, nitrogen and sulphur in biodegradable pots made of 50\%B:50\%BP and 30\%B:70\%BP. Statistical Analysis System (SAS) software version 9.2 was used for the statistical analysis.

\section{Results and discussion}

\section{Decomposition of empty biodegradable pots on the ground}

Disposal of plastic waste in the environment is considered to be a big problem due to its very low biodegradability and presence in large quantities (Patil, 2015). Biomaterial made of starch rather than fossil fuel plastics can decompose faster in soil and reduce environmental pollution. Table 1 shows weight loss percentages in both variants of biodegradable pots - B50\% : BP50\% and B30\% : BP70\%over 60 days, during decomposition on the ground. The weight losses in biodegradable pot B50\%: BP50\% and biodegradable pot B30\% : BP70\% did not differ significantly after decomposing on the ground after 20 days. Weight losses of both biodegradable pots (25-26.37\%) were consistent with the weight loss of bioplastic pot obtained by Liew and Khor (2015), who also produced biodegradable pots using $75 \%$ tapioca starch. Initial rapid degradation of the readily degradable material made of starch and banana peels has also been observed by Cai et al. (2018). Weight losses percentages of both pots increased after 40 days 
Table 1 Weight loss percentages in biodegradable pots made of different ratios of biomaterials and banana peels (pots without soil medium)

\begin{tabular}{|l||c|c|c|}
\hline \multirow{2}{*}{$\begin{array}{l}\text { Pots made of different ratios of } \\
\text { biomaterials (B): banana peels (BP) }\end{array}$} & $\mathbf{3}$ & \multicolumn{2}{c|}{ Weight loss percentages over days (\%) } \\
\cline { 2 - 4 } & $\mathbf{2 0}$ days & $\mathbf{4 0}$ days & $\mathbf{6 0}$ days \\
\hline \hline B50\% : BP50\% & $26.37^{\mathrm{a}} \pm 0.66$ & $31.06^{\mathrm{a}} \pm 2.15$ & $35.86^{\mathrm{b}} \pm 4.60$ \\
\hline B30\% : BP70\% & $25.00^{\mathrm{a}} \pm 0.12$ & $30.31^{\mathrm{a}} \pm 3.74$ & $39.38^{\mathrm{a}} \pm 3.14$ \\
\hline
\end{tabular}

Different letters in the same column indicate significant differences observed in independent $t$-test at $\alpha=0.05$ and \pm indicate standard error $(n=3)$

(30.06-31.31\%). Weight loss in biodegradable pot with ratio $\mathrm{B} 30 \%$ : $\mathrm{BP} 70 \%$ was significantly higher $(39.38 \%)$ than in biodegradable pot with ratio B50\% : BP50\% (35.86\%) after 60 days of decomposing on the ground. This result indicates that the higher content of banana peels accelerates the microbial decomposition in the biodegradable pot. High content of carbohydrate in banana peels (Vu et al., 2017) increases the decomposition activities of microorganisms, since simple sugar substance is easier to be broken down by it (Cai et al., 2018).

\section{Decomposition of biodegradable pots (filled with soil medium) on the ground}

Another experiment included filling of biodegradable pots with soil; decomposition took 60 days on the ground as well. Data in Table 2 show the weight loss percentages in biodegradable pot with ration 50\%: $50 \%$ - weight loss was significantly higher $(51.66 \%)$ than in biodegradable pot with ratio $\mathrm{B} 30 \%$ : $\mathrm{BP} 70 \%(46.41 \%)$. This finding is contradictory to results presented by Liew and Khor (2015), who reported that higher weight loss occurred in the bioplastic pot made of material with higher cellulose content. This could be attributed to the lower tensile strength of biodegradable pot with lower banana peel content, resulting in the increase of weight loss percentage when the biodegradable pot with ratio $\mathrm{B} 50 \%$ : $\mathrm{BP} 50 \%$. was filled with soil. Tensile strength is directly proportional to cellulose content (Ververis et al., 2003). Furthermore, Ullah et al. (2011) also reported that material with higher glycerol concentration biodegraded faster than material with lower glycerol concentration. Authors argued that this was due to the poor strength and bonding between the solid waste and glycerol within the material.

\section{Total carbon $(\mathrm{C})$, nitrogen $(\mathrm{N})$ content and $\mathrm{C} / \mathrm{N}$ ratio of biodegradable pots}

The effect of initial litter quality has been reported to be one of the key drivers of decomposition (Bradford et al., 2016). The $\mathrm{C} / \mathrm{N}$ ratio of residues is a main factor affecting microbial mineralization of $\mathrm{N}$ in crop residues (Vigil and Kissel, 1991; Tian et al., 1992). Increases in C mineralization caused by nitrogen fertilization have been positively related to labile $C$ concentration (Ding et al., 2010). Table 3 shows total content of $\mathrm{C}, \mathrm{N}$ and $\mathrm{C} / \mathrm{N}$ ratio of both biodegradable pots. Total content of $C$ in biodegradable pots made of banana peels was higher than total $\mathrm{C}$ content in banana peels (Odedina et al., 2017). Total C content in biodegradable pot with ration $\mathrm{B} 50 \%$ : $\mathrm{BP} 50 \%$ was significantly higher $(42.18 \%)$ than in biodegradable pot with ratio B30\% : BP70\% (41.50\%). Cellulose polymerization during biomaterial production may have increased the total $\mathrm{C}$ content of the biodegradable pots. Since studies (Essien et al., 2005; Kalemelawa et al., 2012) have shown that banana peels are rich in protein and amino acids, the higher $\mathrm{N}$ content was expected to be in biodegradable pot with ratio B30\% : BP70\%. Therefore, biodegradable pot with higher content of banana peels had higher nitrogen content. The $\mathrm{C} / \mathrm{N}$ ratio of biodegradable pot with ratio $\mathrm{B} 50 \%$ : BP50\% was significantly higher (137.67) than of biodegradable pot with ratio B30\%: BP70\% (110.19). It is likely due to higher total $\mathrm{N}$ content in biodegradable pot with ratio $\mathrm{B} 30 \%$ : $\mathrm{BP} 70 \%$, resulting in the lower $\mathrm{C}$ in the biodegradable pot with higher content of banana peels.

Table 2 Weight loss percentages of biodegradable pots with different ratios of biomaterials and banana peels (pots filled with soil medium)

\begin{tabular}{|l|c|}
\hline Pots with different ratios of biomaterials (B): banana peels (BP) & Weight loss percentage after 60 days decomposition (\%) \\
\hline \hline B50\% : BP50\% & $51.66^{\mathrm{a}} \pm 0.79$ \\
\hline B30\% : BP70\% & $46.41^{\mathrm{b}} \pm 2.29$ \\
\hline
\end{tabular}

Different letters in the same column indicate significant differences observed in independent $t$-test at $\alpha=0.05$ and \pm indicate standard error $(n=3)$

Table 3 Total carbon, nitrogen content and C/N ratio of biodegradable pots

\begin{tabular}{|l|c|c|c|}
\hline $\begin{array}{l}\text { Pots with different ratios of } \\
\text { biomaterials (B): banana peels (BP) }\end{array}$ & Total Carbon (\%) & Total Nitrogen (\%) & C/N Ratio \\
\hline B50\% : BP50\% & $42.18^{\mathrm{a}} \pm 0.13$ & $0.31^{\mathrm{b}} \pm 0.01$ & $137.67^{\mathrm{a}} \pm 4.40$ \\
\hline B30\% : BP70\% & $41.50^{\mathrm{b}} \pm 0.11$ & $0.38^{\mathrm{a}} \pm 0.00$ & $110.19^{\mathrm{b}} \pm 2.23$ \\
\hline
\end{tabular}

Different letters in the same column indicate significant differences observed in independent $t$-test at $\alpha=0.05$ and \pm indicate standard error $(n=3)$ 
A higher $\mathrm{C} / \mathrm{N}$ ratio found in the biodegradable pot with ratio $\mathrm{B} 50 \%$ : $\mathrm{BP} 50 \%$ explains a lower weight loss percentage when the empty biodegradable pot B50\% : BP50\% was left to decompose on the ground.

\section{Conclusions}

A higher $\mathrm{C} / \mathrm{N}$ ratio found in the biodegradable pot with ratio $\mathrm{B} 50 \%: \mathrm{BP} 50 \%$ explains a lower weight loss percentage after the empty biodegradable pot B50\%:BP50\% was left to decompose for more than 60 days on the ground. Conversely, weight loss of biodegradable pot with ratio of $\mathrm{B} 50 \%$ : BP50\% was higher when the pot was filled with soil during 60 days-long decomposition on the ground. It is attributed to lower content of banana peels decreasing the tensile strength of biodegradable pot, making it highly decomposable. Biodegradable pot with ratio $\mathrm{B} 30 \%$ : BP70\% is better than pot with ratio $\mathrm{B} 50 \%$ : $\mathrm{BP} 50 \%$ in terms of degradability. Further studies are underway to increase the quality (tensile strength) of biodegradable pot made of banana peels.

\section{Acknowledgement}

We express our gratitude to Universiti Malaysia Perlis for providing the facilities to support our research work related to the weight loss of biodegradable pots. This research did not receive any specific grant from funding agencies in the public, commercial, or not-for-profit sectors.

\section{References}

BRADFORD, M. A. - BERG, B. - MAYNARD, D. S. - WIEDER, W. R. WOOD, S. A. 2016. Understanding the dominant controls on litter decomposition. In Journal of Ecology, vol. 104, no. 1, pp. 229-238. BRIASSOULIS, D. - BABOU, E. - HISKAKIS, M. - SCARASCIA, G. PICUNO, P. - GUARDE, D. - DEJEAN, C. 2013. Review, mapping and analysis of the agricultural plastic waste generation and consolidation in Europe. In Waste Management Research, vol. 3, no. 12, pp. 1262-1278.

CAI, L. - CHEN, T. B. - ZHENG, S. W. - LIU, H. T. - ZHENG, G. D. 2018. Decomposition of lignocellulose and readily degradable carbohydrates during sewage sludge biodrying, insights of the potential role of microorganisms from a metagenomic analysis. In Chemosphere, vol. 201, pp. 127-136.

DING, W. - YU, H. - CAI, Z. - HAN, F. - XU, Z. 2010. Responses of soil respiration to $\mathrm{N}$ fertilization in a loamy soil under maize cultivation. In Geoderma, vol. 155, pp. 381-389.

ESSIEN, J. P. - AKPAN, E. J. - ESSIEN, E. P. 2005. Studies on mould growth and biomass production using waste banana peel. In Bioresource Technology, vol. 96, pp. 1451-1456.
KALEMELAWA, F. - NISHIHARA, E. - ENDO, T. - AHMAD, Z. YEASMIN, R. - TENYWA, M. M. - YAMAMOTO, S. 2012. An evaluation of aerobic and anaerobic composting of banana peels treated with different inoculums for soil nutrient replenishment. In Bioresource Technology, vol. 126, pp. 375-382.

KAŽIMÍROVÁ, V. - GADUŠ, J. - GIERTL, T. 2018. Verification of suitability of substrate composition for production and quality of biogas. In Acta Technologica Agriculturae, vol. 21, pp. 115-118.

LIEW, K. C. - KHOR, L. K. 2015. Effect of different ratios of bioplastic to newspaper pulp fibres on the weight loss of bioplastic pot. In Journal of King Saud University-Engineering Sciences, vol. 27, pp. 137-141.

ODEDINA, M. J. - CHARNNOK, B. - SARITPONGTEERAKA, K. CHAIPRAPAT, S. 2017. Effects of size and thermophilic pre-hydrolysis of banana peel during anaerobic digestion, and biomethanation potential of key tropical fruit wastes. In Waste Management, vol. 68, pp. 128-138.

PATIL, P.S. 2015. Behavior of concrete which is partially replaced with waste plastic. In International Journal of Innovative Technology and Exploring Engineering, vol. 4, no. 11, pp. 1-3.

RAMAKRISHNAN, N. - SHARMA, S. - GUPTA, A. - ALASHWAL, B. Y. 2018. Keratin based bioplastic film from chicken feathers and its characterization. In International Journal of Biological Macromolecules, vol. 111, pp. 352-358.

TIAN, G. - KANG, B. T. - BRUSSAARD, L. 1992. Biological effects of plant residues with contrasting chemical compositions under humid tropical conditions-decomposition and nutrient release. In Soil Biology and Biochemistry, vol. 24, pp. 1051-1060.

TOCK, J. Y. - LAI, C. L. - LEE, K. T. - TAN, K. T. - BHATIA, S. 2010. Banana biomass as potential renewable energy resource: A Malaysian case study. In Renewable Energy and Sustainable Energy Reviews, vol. 14, no. 2, pp. 798-805.

ULLAH, A. - VASANTHAN, T. - BRESSLER, D. - ELIAS, A. L. - WU, J. 2011. Bioplastics from feather quill. In Biomacromolecules, vol. 12, no. 10, pp. 3826-3832.

VERVERIS, C. - GEORGHIOU, K. - CHRISTODOULAKIS, N. - SANTAS, P. - SANTAS, R. 2003. Fiber dimensions, lignin and cellulose content of various plant materials and their suitability for paper production. In Industrial Crops and Products, vol. 19, pp. 245-254.

VIGIL, M. F. - KISSEL, D. E. 1991. Equations for estimating the amount of nitrogen mineralized from crop residues. In Soil Science Society of America Journal, vol. 55, pp. 757-761.

VU, H. T. - SCARLETT, C. J. - VUONG, Q. V. 2017. Effects of drying conditions on physicochemical and antioxidant properties of banana (Musa cavendish) peels. In Drying technology, vol. 35, no. 9, pp. 1141-1151.

WEBB, H. K. - ARNOTT, J. - CRAWFORD, R. J. - IVANOVA, E. P. 2013. Plastic degradation and its environmental implications with special reference to poly(ethylene terephthalate). In Polymer, vol. 5, pp. $1-18$. 